\title{
Stress in children pathology: From psychosomatics to molecular biology
}

\author{
Sorin Buzinschi
}

Faculty of Medicine, Transilvania University, Brasov, Romania

ABSTRACT
During childhood, 3 levels of stress were proposed: positive, tolerable and toxic. The toxic stress produced by the
strong, frequent and prolonged activation of the body's response systems is a generator of behavioral and somatic
sequelae. Child abuse is present in all social media in different countries. The absence of basic care has devastat-
ing effects on social and cognitive development, as found in institutionalized children. Attachment behavior and fear
memory are considered stress-related biological systems. The response to stress is driven by the dynamics of
cortisol secretion and its interaction with its cellular receptor. It plays a central role in the response to aggression
through the process of methylation, decreased gene expression in the hippocampus and increased response to
stress. Stress treatment is variable in efficiency and involves preventive measures (family and community), at
school, bullying, psychological counseling, trauma-focused psychotherapy, cognitive therapy, through music.
Keywords: stress, toxic stress, cortisol, methylation, treatment

\section{INTRODUCTION}

Stress accompanies human experience throughout life. Adverse or traumatic childhood experiences have an impact on mental and physical health during life. Moreover, the effects of maternal nutritional, physical or mental restrictions may be transmitted transplacental to children. Stress known as a fundamental reaction to physical, behavioral, or social stimuli is recognized as a source of major influences on human physiology and behavior. The multidisciplinary approach to stress response involves various scientific fields such as psychology, neurobiology, the study of metabolism, genomics, epigenetics or epidemiology. In a comprehensive review of the effects of childhood stress on later life Shokonoff et al. (1) representing the views of the US Committee on Child Psychosocial and Family Health, seeks to explain the mechanisms by which childhood adversity produce adult health disorders. Since the end of the twentieth century, the infectious etiology of children's pathology has been dominated by other problems such as physical, sexual, emotional abuse, exposure to violence, family disorganization, economic, social, racial and ethnic inequalities. "Excessive" TV shows, and the influence of new communication technologies. The avalanche of potentially traumainducing pressures has been correlated with anxiety, depression, bipolar disorder and post-traumatic stress disorder (2). Awareness of these issues is important because adult health promotion programs must begin with the significant protection of children in all stages of their development, being overall markers of the degree of social evolution of the countries involved. Hierarchy of stress During childhood, 3 levels of stress response were proposed: positive, tolerable and toxic $(1,3)$.

\section{THE THREE LEVELS OF STRESS}

Positive stress is a physiological state in which the compensatory mechanisms are engaged for a short time, and the response to stress by increasing circulating cortisol is followed by a return to baseline in a short time. This type of reaction involves a mild or moderate response of the regulatory systems and is manifested in the infant by tachycardia and agitation. Such "problems" are generated by the time of vacci- 
nation, the first day at the nursery, the resumption of service by the mother (short-term separation), etc Manifestations of stress were recorded in newborns during medical procedures (clinical examination, blood sampling, circumcision, etc.) attested to significant increases in cortisol and ACTH (1).

Moderate stress can increase resilience and temper its effects over time $(4,5)$. In other words, overcoming stress in the first periods of life through light exposures is necessary to cope with those who will follow in adulthood. The "tolerable" response to stress is produced by more intense negative experiences, but of limited duration (illness in the family, separation or divorce of parents, accidents, etc.). It causes the activation of stress response systems and can generate moderate health effects. The protective behavior of the family and the entourage blurs the scope of the response and favors the return to baseline. If the child does not benefit from protection in these situations, the stress may become persistent.

Severe or "toxic" stress occurs through the accumulation of negative feelings for a long time (weeks, months, years). The child is unable to overcome this type of aggression alone. It can occur in conditions of physical or sexual abuse of children, neglect, drug use in the family, maternal depression, war life, etc. As a result, stress response systems are strongly activated, frequently, for a long time $(1,3,6)$.

Severe stress induces high and prolonged levels of stress hormones that are released into the systemic circulation. As a result, there are changes in metabolic and other regulations that affect the brain circuits, produce long-term disruptions of learning processes, memory and behavior being the cause of mental illness caused by stress $(1,7,8)$. Late awareness of toxic stress is physical, emotional, psychological and social (10)

TABLE 1. Long-term side effects of toxic stress suffered by children; they may become manifest during adulthood

\begin{tabular}{|l|l|}
\hline Physical changes & $\begin{array}{l}\text { Heart disease, hypertension, } \\
\text { extrasystoles, frequent episodes of } \\
\text { headache, increased susceptibility to } \\
\text { infections }\end{array}$ \\
\hline Emotional changes & $\begin{array}{l}\text { Depression, lack of energy and } \\
\text { motivation. Personality disorders such as } \\
\text { violence or disobedience }\end{array}$ \\
\hline $\begin{array}{l}\text { Psychological } \\
\text { changes }\end{array}$ & $\begin{array}{l}\text { Anxiety, increased irritability and } \\
\text { aggression, frustration, isolation from } \\
\text { family and friends, nightmares }\end{array}$ \\
\hline Behavioral changes & $\begin{array}{l}\text { Manifestations of regression, change in } \\
\text { eating habits, hyperactivity }\end{array}$ \\
\hline
\end{tabular}

Adverse experiences of the child abuse is a source of toxic stress and a public health problem all over the world affecting children in all societies and social classes. In the USA, 1 in 7 children between 2 and 17 years old have gone through experiences related to physical abuse, sexual abuse, neglect, emotional abuse, the authors being $77 \%$ family (6). In Romania in 2020, through its investigations, the Save the Children Association identified a number of 11,031 children in situations of abuse, neglect and exploitation (physical, emotional, sexual) (11). A number of 22,136 children presented with mental health disorders, including anxiety, depression, attachment disorders, according to data taken from the National Strategy for Child and Adolescent Mental Health between January and October 2014 (15). It is mentioned that 77,900 children have one or both parents working abroad, and $35.8 \%$ of children in Romania is at risk of poverty / social exclusion (12).

\section{INSTITUTIONALIZED CHILDREN}

The absence of some basic care has devastating effects on social and cognitive development. Infants raised institutionally have delays in physical development, atypical responses to stress, cognitive dysfunction and social behavior (13). Children raised in the institutional environment randomly discharged into family placement before the age of 2 have significantly higher cognitive and social gains compared to children who remain in orphanages until older ages (14). There were 18,197 children in placement centers in Romania in 2017, and 5,309 were deinstitutionalized (15). Since January 2020, the Romanian Government has banned the institutionalization of children in old-type centers, allowing only the reception of those with severe functional dysfunctions.

\section{COMPONENTSOF THESTRESSRESPONSE}

For young children who perceive the world as a threatening place, a wide range of situations can trigger anxious behavior, decreased ability to learn and interact socially (3). Attachment theory and fear memory can be included in this framework.

\section{Attachment theory}

It has been found that there is a link between maternal physical contact, the degree of care and the amplitude of the stress response, careful maternal care being related to the development of the immature emotional system of the infant. Known as the theory of attachment, it objectifies the young child's need for defense, peace and food. The presence of the mother as an attachment figure allows the young child to explore the environment (16), the visual contact being a condition of assurance. The presence of 
the attachment figure (usually the mother) influences the child's cortisol secretion, being higher in its absence. Attachment behavior is considered a biological system interrelated with stress and fear. It is activated under stress when the mother's lack (or eye contact) increases the manifestations of fear and her "urgent" demand. The period of formation and diversification of attachment is evident in the first 5 years of life; in the absence of it, there are developmental consequences such as increased aggression and impaired intelligence (16).

Attachment can be defined as a deep and lasting connection
between 2 people in which each seeks closeness and feels
more secure in the presence of the attachment figure.
Attachment behavior in adults to children includes sensitive
and appropriate responses to their needs. This behavior is
universal in all cultures. Attachment theory explains how
the parent-child relationship appears and how it influences
further development. Attachment is most likely formed to
the person who responds accurately to the child's signals, not
to the person who spends the most time with him (sensitive
responses). Attachment involves the specific behavior of the
child by seeking the proximity of the attachment figure in
situations of discomfort or threat (16).

In post-institutionalized children, difficulties were observed in the formation of emotional attachment to adoptive mothers and recognition of facial expressions (joy, upset, etc.).

\section{Fear memory}

In general, fear is a behavioral axiom by which the body anticipates adverse events based on past experiences. However, in children the first manifestations of fear appear between 6 and 12 months when new figures or new situations appear. In preschoolers, the manifestations of fear are accentuated by the family environment and stimulated by imagination ("wolf", "snake", darkness). It is difficult for them to differentiate between real and imaginary. These constructions dissipate spontaneously around the age of 7-8 years. The genetic component of fear has been estimated to be between 34 and $43 \%$ in studies of twins (17). Chronic and intense fear caused by real, serious situations, such as aggression, physical abuse, sexual abuse, abandonment, etc. affect the development of the stress response system and influence the processing of emotional memory (3).

\section{MOLECULAR BIOLOGY OF STRESS}

The response to stress is organized on 2 correlated structures: the sympatho-adrenomedular system (SAM) and the hypothalamic-pituitary-adrenal axis (HPA).
The sympatho-adrenomedullary system (SAM) is the sympathetic part of the autonomic nervous system that causes the release of adrenaline $(80 \%)$ and norepinephrine (20\%) from the adrenal medulla, hormones that determine the reaction "run or fight" through adrenergic receptors. The effects of its activation are: increased heart rate, vasodilation in muscle tissue, intestinal and skin vasoconstriction, increased blood sugar. SAM contains perfectly orchestrated elements that define the immediate response to stress, regardless of its nature. Ex emotional stress produced by an exam is accompanied by tachypnea, increased BP, palm sweating.

In contrast to SAM, Hypothalamic-pituitary-adrenal system (HPA) produces glucocorticoids (GC); to cortisol. Compared to adrenaline, which does not cross the blood-brain barrier in significant proportions, cortisol acts on both the brain and the body by acting on cellular receptors. Once activated, they transmit information to the cell nucleus, the level at which the transcription of some genes is regulated. The stressful stimulus triggers a succession of processes that ultimately triggers the release of ACTH in the anterior pituitary gland. Entered into circulation $\mathrm{ACTH}$ binds to the cellular receptors of the adrenal cortex producing the release of cortisol that diffuses into the systemic vascular circuit. In SN, GC receptors are present in all cell types but have a higher concentration in stress regulatory centers such as the hypothalamic paraventricular nucleus, hippocampus, amygdala, prefrontal cortex (18).

\section{GLUCOCORTICOID RECEPTOR (CR) GENE: THE KEY TO THE STRESS RESPONSE?}

Early research on the link between CR and behavior by Liu et al. (19) showed that variations in the maternal care of rodent chicks have as an effect differences in behavioral and endocrine response to stress. Pups neglected in the first week of life were characterized by increased methylation of the glucocorticoid receptor (CR), low levels of the receptor in the hippocampus and increased response to stress as adults. Rodent pups cared for by their mothers showed decreased DNA methylation of RC in the hippocampus, increased GR gene expression, decreased hippocampal sensitivity to glucocorticoid hormones in response to acute stress, and easier stress management later. These changes were maintained during adulthood as an argument that maternal care programs the stress responses of offspring $(7,20,21)$. Numerous data suggest that parental care establishes long-lasting phenotypic differences in offspring through epigenetic signals. 


\section{MATERNAL STRESS DURING PREGNANCY}

The maternal stress during pregnancy imprints the stress response of the offspring being transmitted from one generation to another epigenetically. Oberlander et al. (34) found that prenatal exposure of the fetus to the mother's depressive / anxious behavior in the 3rd trimester of pregnancy is associated with increased methylation of the CR gene in umbilical cord mononuclear cells and increased salivary cortisol response in of stress. Under physiological conditions, there is a gradient of glucocorticoids 100-1,000 times higher in the maternal circulation than in the fetal one (29). The low-protein diet of rodents decreased the activity of the placental enzyme 11 $\beta$-hydroxysteroid dehydrogenase (11ßHSD2). Under standard conditions, it largely converts active glucocorticoids into forms without physiological activity, being a barrier to maternal corticosterone access to the fetus. If the placental barrier is not fully functional, the excessive passage of glucocorticoids of maternal origin into the fetal circulation activates specific receptors, stimulates early cell differentiation, low birth weight, subsequent somatic and behavioral changes (anxiety) (28-30). In pregnant women in the last trimester of pregnancy, the increase in placental $11 \beta-H S D 2$ activity was parallel to the increase in circulating levels of glucocorticoids; in infants with intrauterine growth restriction, a decrease in enzyme activity and its protective role was evident (30). The relationship between nutritional deprivation during pregnancy, fetal development and subsequent pathology was studied in a "natural experiment" caused by the famine in the Netherlands during World War II. The evolution of children born during this period, followed for 60 years, showed lasting epigenetic changes and a pathology centered on obesity, cardiovascular diseases, depression or schizophrenia (23-25). In people who endured periods of severe stress in childhood, there was an increase in methylation of the RC gene, a decrease in gene expression in the hippocampus and an increase in the incidence of psychiatric disorders. Postmortem investigations in subjects who died by suicide identified similar changes in the conditions in which they suffered childhood traumas (26).

Epigenetics is the innate but reversible regulation of various functions of the genome that occur independently of DNA sequences. Epigenetic regulation is mediated by DNA methylation along with changes in histones and microRNAs. DNA methylation occurs by attaching the methyl group (CH3) to a specific area of the gene by acting as a pedal between the open (active) and closed (partially inactive) form of the gene. The degree of DNA methylation can influence the increase or decrease of gene expression and influence behavior, i.e. the $\mathrm{CH} 3$ radical can decisively influence a person's life trajectory.

\section{EPIGENETIC PLASTICITY}

Included in cellular memory, epigenetic modulation becomes a regulatory factor in response to food deficiencies, toxic to the environment, severe disturbances of the family and society (7). Negative prenatal (malnutrition, maternal depression, drug exposure) or postnatal (previous, toxic stress, etc.) experiences are not "forgotten" but are included in the architecture of the developing brain through the epigenome (22). "Biological memory" associated with these epigenetic changes can affect multiple organ systems and increase the risk of physical and mental problems while also affecting the subsequent ability to learn and behavior (22). Maternal stress in war conditions has a strong effect on newborns, producing decreases of up to $35 \%$ of birth weight by RC methylation of newborns (26). Kuzawa (Northwestern University), through his contribution to an extensive study of behavioral epigenetics (27), shows how epigenetic regulation establishes stable changes in nutrition during sensitive periods of development. Thus in the Philippines the growth of the infant is "calibrated" by the amount of leptin (hormone that inhibits hunger) in breast milk, a signal of maternal energy history and its nutritional resources.

\section{THE LIFE TRAJECTORY OF CHILDREN SUBJECTED TO STRESS}

The in-depth understanding of how parental care and social influences contribute to the construction of children's phenotype is largely due to the acquisition of epigenetics. The contribution of parents in the formation of the child was also related to the methylation of genes with a role in various biological systems, persistent changes in adolescence and adulthood (31). The parent-child relationship generates life experiences that repeatedly initiate cascades of biological signals that increase the expression of genes with a role in homeostasis. Poor care and the hostile environment alter the functioning of the HPA axis with subsequent repercussions on behavior and metabolism. Their substrate is the methylation of the glucocorticoid receptor (CR) initially demonstrated in the hippocampus, the disorder of many other genes such as MIF (macrophage migration inhibitory factor) and stress-related systems (oxytocin, serotonin, neurotrophins, immune system genes, etc.) (31). Disorder of parent-child family relationships produces increases in cortisol in preschool, high values being predictive of behavioral and emotional problems at school age (18). If positive stress can be considered a factor included in the adaptation program, psychosocial stress is incorporated into biological reality through the se- 
quence of stress $>$ methylation $>$ expression of genes $>$ phenotype (26). Contact with other children and adults involves preschoolers developing social skills, controlling inappropriate behavior, communication, modulating emotions. After entering the community, children between 2-4 years old show mostly increases in cortisol. Those with high values of cortisolemia are less sociable, less able to regulate negative emotions and aggression as the equivalent of the level of stress felt towards unpleasant children (18). In childhood and adolescence, the social environment shapes cognitive development (8), behavior, the ability to insert in the community and anxiety. An extreme case is the separation from the family, as is the case of some immigrant children, who have developed severe behavioral consequences (32). A legitimate question is whether dysfunctional stress can have long-lasting effects for the rest of your life. The long-term consequences of toxic stress in children listed in various studies $(1,3,5,6,8,9)$ contain essentially the following elements:

- Children under severe stress are part of the risk group for anxiety and depression disorders, psychiatric disorders, post-traumatic stress syndrome, borderline and antisocial personality, tendency to use drugs;

- Meta-analyzes found that approximately half of patients with depression (46\%) and bipolar disorder $(57 \%)$ were victims of childhood abuse;

- Toxic stress due to increased levels of circulating cortisol causes damage to the hippocampus, the brain area involved in learning and memory. Impaired brain circuits lower the threshold for perceiving stress and increase the reactivity to life-threatening adverse experiences.

- The late effects of prolonged stress can be correlated with cardiovascular and metabolic disorders

- High levels of stress hormones, including cortisol negatively influence the body's immune response and increase vulnerability to infections

It should be noted that traumatic childhood experiences alone are not enough to cause mental illness, as some subjects with a history of severe childhood abuse remain healthy (33). It is not clear enough to what extent the genetic contribution can influence the response to adverse experiences; in this sense, the role of a variant of the serotonin transporter gene that would increase the risk for anxiety and depression was evoked (10). Based on some evidence, epigenetics was considered the "missing piece" in understanding the context in which negative childhood events induce psychological disorders (33), being along with the genome, the foundation of phenotype construction.

\section{TREATMENT}

There is currently no specific epigenetic treatment for stress. The effect of therapeutic interventions should be to regulate cortisol secretion which leads to decreased stress responses. In practice, several lines of treatment were imposed, of which we mention:

Prevention: support and positive attitude from parents, constant help for resilience. It is important to control the care staff at home or in the nursery, to listen carefully to the child's reports.

Therapy: avoidance of traumas and permanent stressors at home and in the community (conflicts, school stress, bullying), family involvement in activities with a positive impact (trips, games), father's participation in activities that require effort (for trust). Parental intervention of mutual support with educators, teachers.

Psychological counseling, trauma-focused psychotherapy, treatment in psychiatric services (+/-), cognitive therapy, music therapy, support of volunteer groups.

Play therapy if conditions allow (communities, hospitals).

All these data have a pure book content if they are not accompanied by family balance and economic stability.

\section{CONCLUSIONS}

The toxic stress produced by the strong, frequent and prolonged activation of the body's response systems is a generator of behavioral and somatic sequelae. Attachment behavior and fear memory are considered stress-related biological systems. Stress treatment is variable in efficiency and involves preventive measures (family and community) at school, bullying counteracting, psychological counseling, trauma-focused psychotherapy, cognitive therapy, through music.

Conflict of interest: none declared Financial support: none declared 


\section{REFERENCES}

1. Shonkoff JP, Garner AS; Committee on Psychosocial Aspects of Child and Family Health; Committee on Early Childhood, Adoption, and Dependent Care; Section on Developmental and Behavioral Pediatrics. The lifelong effects of early childhood adversity and toxic stress. Pediatrics. 2012 Jan;129(1):e232-46.

2. Jiang S, Postovit L, Cattaneo A, Binder EB, Aitchison KJ. Epigenetic Modifications in Stress Response Genes Associated With Childhood Trauma. Front Psychiatry. 2019 Nov 8;10:808.

3. National Scientific Council on the Developing Child, 2010. Persistent Fear and Anxiety Can Affect Young Children's Learning and Development. Available at: https://developingchild.harvard.edu/ wp-content/uploads/2010/05/Persistent-Fear-and-Anxiety-Can-AffectYoung-Childrens-Learning-and-Development.pdf.

4. Griffiths B, Hunter G. Neuroepigenetics of Stress. Neuroscience. 2014;275:420-435.

5. Schiele MA, Gottschalk MG, Domschke K. The applied implications of epigenetics in anxiety, affective and stress-related disorders - A review and synthesis on psychosocial stress, psychotherapy and prevention. Clin Psychol Rev. 2020 Apr;77:101830.

6. U.S. Department of Health and Human Services - Centers for Disease Control and Prevention. The effects of childhood stress on health across the lifespan. Available at: https://stacks.cdc.gov/view/ $\mathrm{cdc} / 6978$.

7. Murgatroyd C, Spengler D. Epigenetics of early child development. Front Psychiatry. 2011 Apr 18;2:16.

8. Guinosso S, Johnson S, Riley A. Multiple adverse experiences and child cognitive development. Pediat Res. 2016;79:220-226.

9. Lippard ETC, Nemeroff CB. The Devastating Clinical Consequences of Child Abuse and Neglect: Increased Disease Vulnerability and Poor Treatment Response in Mood Disorders. Am J Psychiatry. 2020 Jan 1;177(1):20-36.

10. Gunnar MR, Barr RG. Stress, Early Brain Development, and Behavior. Infants \& Young Children 1998;11(1):1-14.

11. Gradinaru C, Stanculeanu D. Analiza serviciilor de sanatate mintala pentru copiii din Romania. Comunicare Salvati Copiii, 2020.

12. Paraschiv R. Saracia si excluziunea sociala - impactul asupra dreptului la educatie. Comunicare Salvati Copiii Romania, 2021.

13. van IJzendoorn MH, Palacios J, Sonuga-Barke EJ, Gunnar MR, Vorria P, McCall RB, LeMare L, Bakermans-Kranenburg MJ, Dobrova-Krol NA, Juffer F. Children in Institutional Care: Delayed Development and Resilience. Monogr Soc Res Child Dev. 2011 Dec;76(4):8-30.

14. Moore SR, McEwen LM, Quirt J, Morin A, Mah SM, Barr RG, Boyce WT, Kobor MS. Epigenetic correlates of neonatal contact in humans. Dev Psychopathol. 2017 Dec;29(5):1517-1538.

15. Strategia Nationala pentru Sanatatea Mintala a Copilului si Adolescentului 2016-2020. Available at: https://sgg.gov.ro/new/ wp-content/uploads/2016/11/Anexa-Strategie.pdf.

16. McLeod S. Attachment theory. Available at: https://www. simplypsychology.org/attachment.html.

17. Hettema JM, Annas P, Neale MC, Kendler KS, Fredrikson M. A twin study of the genetics of fear conditioning. Arch Gen Psychiatry. 2003 Jul;60(7):702-8.

18. Gunnar M, Quevedo K. The neurobiology of stress and development. Annu Rev Psychol. 2007;58:145-73.

19. Liu D, Diorio J, Tannenbaum B, Caldji C, Francis D, Freedman A, Sharma S, Pearson D, Plotsky PM, Meaney MJ. Maternal care, hippocampal glucocorticoid receptors, and hypothalamic-pituitaryadrenal responses to stress. Science. 1997 Sep 12; 277(5332):1659-62.

20. Meaney MJ, Szyf M. Environmental programming of stress responses through DNA methylation: life at the interface between a dynamic environment and a fixed genome. Dialogues Clin Neurosci. 2005; 7(2):103-23.

21. Hunter RG. Epigenetic effects of stress and corticosteroids in the brain. Front Cell Neurosci. 2012 Apr 19;6:18.

22. National Scientific Council on the Developing Child. Early Experiences Can Alter Gene Expression and Affect Long-Term Development. Available at: https://developingchild.harvard.edu/ resources/early-experiences-can-alter-gene-expression-and-affectlong-term-development/.

23. Boekelheide K, Blumberg B, Chapin RE, Cote I, Graziano JH, Janesick A, Lane R, Lillycrop K, Myatt L, States JC, Thayer KA, Waalkes MP, Rogers JM. Predicting later-life outcomes of early-life exposures. Environ Health Perspect. 2012 Oct;120(10):1353-61.

24. Nafee TM, Farrell WE, Carroll WD, Fryer AA, Ismail KM. Epigenetic control of fetal gene expression. BJOG. 2008 Jan;115(2):158-68.

25. Collins N, Roth $\mathrm{T}$. Intergenerational transmission of stress-related epigenetic regulation. In: Tollefsbol T, Provenzi L, Montirosso R (eds.). Developmental Human Behavioral Epigenetics. Academic Press Elsevier, 2021:119-141.

26. Mulligan CJ. Early Environments, Stress, and the Epigenetics of Human Health. Annu Rev Anthropol. 2016;45:233-249.

27. Lester BM, Tronick E, Nestler E, Abel T, Kosofsky B, Kuzawa CW, Marsit CJ, Maze I, Meaney MJ, Monteggia LM, Reul JM, Skuse DH, Sweatt JD, Wood MA. Behavioral epigenetics. Ann N Y Acad Sci. 2011 May; 1226:14-33.

28. Ramo-Fernández L, Boeck C, Koenig AM, Schury K, Binder EB, Gündel H, Fegert JM, Karabatsiakis A, Kolassa IT. The effects of childhood maltreatment on epigenetic regulation of stress-response associated genes: an intergenerational approach. Sci Rep. 2019 Apr 18;9(1):983.

29. Langley-Evans E. Nutrition: A Lifespan Approach. Wiley-Blackwell, 2008.

30. Shams M, Kilby MD, Somerset DA, Howie AJ, Gupta A, Wood PJ, Afnan M, Stewart PM. 11Beta-hydroxysteroid dehydrogenase type 2 in human pregnancy and reduced expression in intrauterine growth restriction. Hum Reprod. 1998 Apr;13(4):799-804.

31. Undernaehrer E, Meier M, Bouvette-Turcot A, Hari Dass S. Long-term epigenetic effects of parental caregiving. In: Tollefsbol T, Provenzi L, Montirosso R (eds.). Developmental Human Behavioral Epigenetics. Academic Press Elsevier, 2021:105-117.

32. Gartland MG, Hidalgo JA, Danaher FS. Case 20-2020: A 7-Year-Old Girl with Severe Psychological Distress after Family Separation. N Engl J Med. 2020 Jun 25;382(26):2557-2565.

33. Weaver I. Epigenetics in Psychology. Available at: https:// openpress. usask.ca/introductiontopsychology/chapiter/epigenetics-inpsychology/.

34. Oberlander TF, Weinberg J, Papsdorf M, Grunau R, Misri S, Devlin AM. Prenatal exposure to maternal depression, neonatal methylation of human glucocorticoid receptor gene (NR3C1) and infant cortisol stress responses. Epigenetics. 2008 Mar-Apr;3(2):97-106. 